$$
\text { DOE/SF/20282-T2 }
$$

INTERNATIONAL THERMONUCLEAR EXPERIMENTAL REACTOR

\title{
Toroid Field Coil Shear Key Installation Study DOE Task No. 22
}

RECEIVED

JUL $2^{9}$ DOS

January 9, 1995

$08 \mathrm{TI}$

Prepared for:

ITER

Joint Central Team

\author{
C. E. Jones \\ R. W. Meier \\ J. L. Yuen
}

Rockwell International

Rocketdyne Division

6633 Canoga Avenue

Canoga Park, CA 91309-7922 
INTERNATIONAL THERMONUCLEAR EXPERIMENTAL REACTOR

Toroidal Field Coil Shear Key Installation Study

\section{TABLE OF CONTENTS}

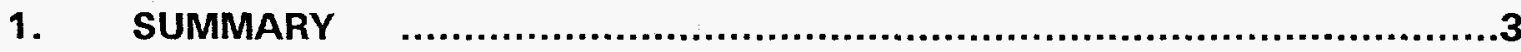

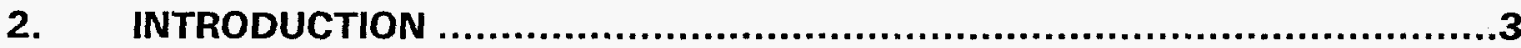

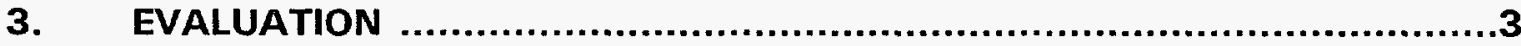

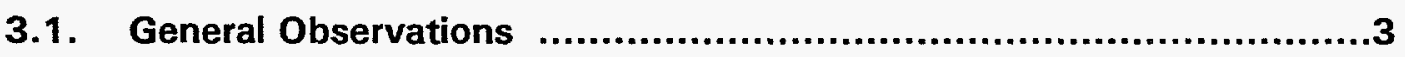

3.2 Initial Coil Characterization ................................................4

3.3 Solenoid Coil in Last - Initial Installation .................................9

3.3.1 Scissor Keys Installation ..........................................

3.3.2 Lower Triangular Keys Installation................................10

3.3.3 Truss Keys Installation ....................................... 12

3.3.4 Upper Triangular Keys Installation ...............................12

3.4 Solenoid Coil in Last - Remote Replacement........................... 13

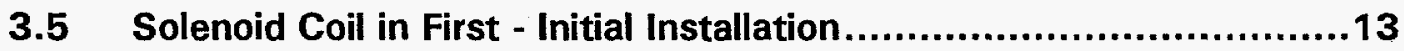

3.5.1 Scissor Keys Installation .......................................13

3.5.2 Lower Triangular Keys Installation..............................13

3.5.3 Truss Keys Installation ..........................................13

3.5.4 Upper Triangular Keys Installation ................................13

3.6 Solenoid Coil in First - Remote Replacement.......................... 15

3.7 Hybrid Installation and Remote Replacement Sequence ...............15

3.7.1 General Observations...........................................15

3.8 TF Coil Shear Keys Installation Time Line.............................. 15

4. TF COIL SHEAR KEYS INSTALLATION TIME LINE $\ldots \ldots \ldots \ldots \ldots \ldots \ldots \ldots \ldots \ldots$

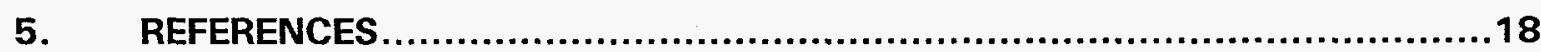

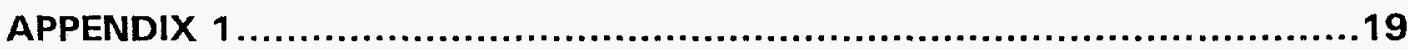




\title{
INTERNATIONAL THERMONUCLEAR EXPERIMENTAL REACTOR
}

\author{
Toroidal Field Coil Shear Key Installation Study
}

DOE Task No. 22

\section{SUMMARY}

Concepts for fitting and installation of the scissor keys, triangular keys, and truss keys in the ITER Toroidal Field (TF) Coil Assembly were developed and evaluated. In addition, the process of remote removal and replacement of a failed TF coil was considered. Two concepts were addressed: 1) Central solenoid (CS) installed last (Naka Option \#1) and 2) Central solenoid installed first (Naka Option \#2). In addition, a third concept was developed which utilized the favorable features of both concepts. A time line for installation was estimated for the Naka Option \#1 concept.

\section{INTRODUCTION}

A concept for fitting and installation of the scissor keys and triangular keys in the ITER TF Coil Assembly has been developed. In addition, the process for remote removal and replacement during repair and maintenance operations is also addressed. Concepts to be considered (as described by J.N. Doggett of Lawrence Livermore National Laboratory (LLNL) in a meeting on September 23, 1994) are: i) Central solenoid installed last and ii) Central solenoid installed first. These two concepts have been named the Naka Option \#1 and \#2, respectively. Descriptions of these options, "Initial Assembly Procedure for the ITER Support Structure and Magnet Components", were presented at Garching, October 46, 1994 and described in References 1 and 2.

\section{EVALUATION}

\subsection{General Observations}

This evaluation is based on the detailed description within the Naka Options \#1 and \#2 documents, References 1 and 2 . Review of both installation concepts identified a fundamental concern.

Characterization of each TF coil half slot and correction, if required, must occur prior to installation into the reactor postion. This would facilitate any corrections to be performed.

The characterization of a slot formed by two mating TF coils occurs after installation in the reactor. These slots may require remachining/refabrication to obtain proper key alignment within the reactor cavity.

Characterization of the shear key slot at assembly is confirmatory in nature to assure alignment within the reactor. To verify slot alignment between two coils, a robot will be aligned to a key slot, a laser probe ${ }^{3}$ will then be inserted into the slot's full length confirming the rear key retainer, then the probe is spirally retracted to characterize the slot and create a 3 dimensional representation of the slot. This data can be used to select the 
correct key(s) from a premachined assortment of keys which are stored in close proximity to the robotic key insertion equipment. This storage container is mobile and can move independently of the robotic key insertion equipment. Alternately, the 3 dimensional slot data can be directly fed to an N/C machine to perform final machining operations of the keys.

The laser profilometry technology is advanced, though state-of-the-art. Description of such a device from Selcom ${ }^{3}$ is found in Appendix 1. This profilometer can be interfaced to a numerically controlled machine tool in order to down load this data to mill/grind the tile shapes from blanks.

\subsection{Initial Coil Characterization}

The TF coils may be delivered to the on-site staging area from the fabrication site in a horizontal position. The coils will be verticalized and secured to a handling device or strongback. Once in the vertical position, the coil would be located in a support device which duplicates the TF coil support, see Figure 1. Figure 2 portrays the TF coil slots being characterized from one side, while Figure 3 demonstrates slot inspection (characterization) occurring simultaneously by two devices, one on each side. Utilizing combined motions of the upper and lower arms, the laser profilometry end effector is moved along each half slot theoretical centerline to measure the half slot. A threedimensional representation can be created and stored for comparison to the representation of the mating coil(s) to confirm the compatibility of the full slot. Slot correction, if required, would occur prior to coil installation in the reactor. Following slot characterization, the first TF coils would be stored vertically until adequate data has been encoded to ascertain the slot dimensions (e.g., four to six coils).

Following evaluation of the initial data, the characterized TF coils are installed in the reactor. All subsequent coils will be characterized just prior to installation into the reactor. Per Naka Option \#1 installation procedure (central solenoid in last), all adjustments are made and the TF coils are ready for key installation. The three measurement devices on the Central Measuring Assembly are removed to allow free access for key installation. The following procedure assumes keys are prepared from the data compiled from the slot inspection data of adjacent magnets and are ready for insertion. A robotic device is lowered into the reactor cavity with a slot inspection device and key insertion end effectors, see Figure 4. 


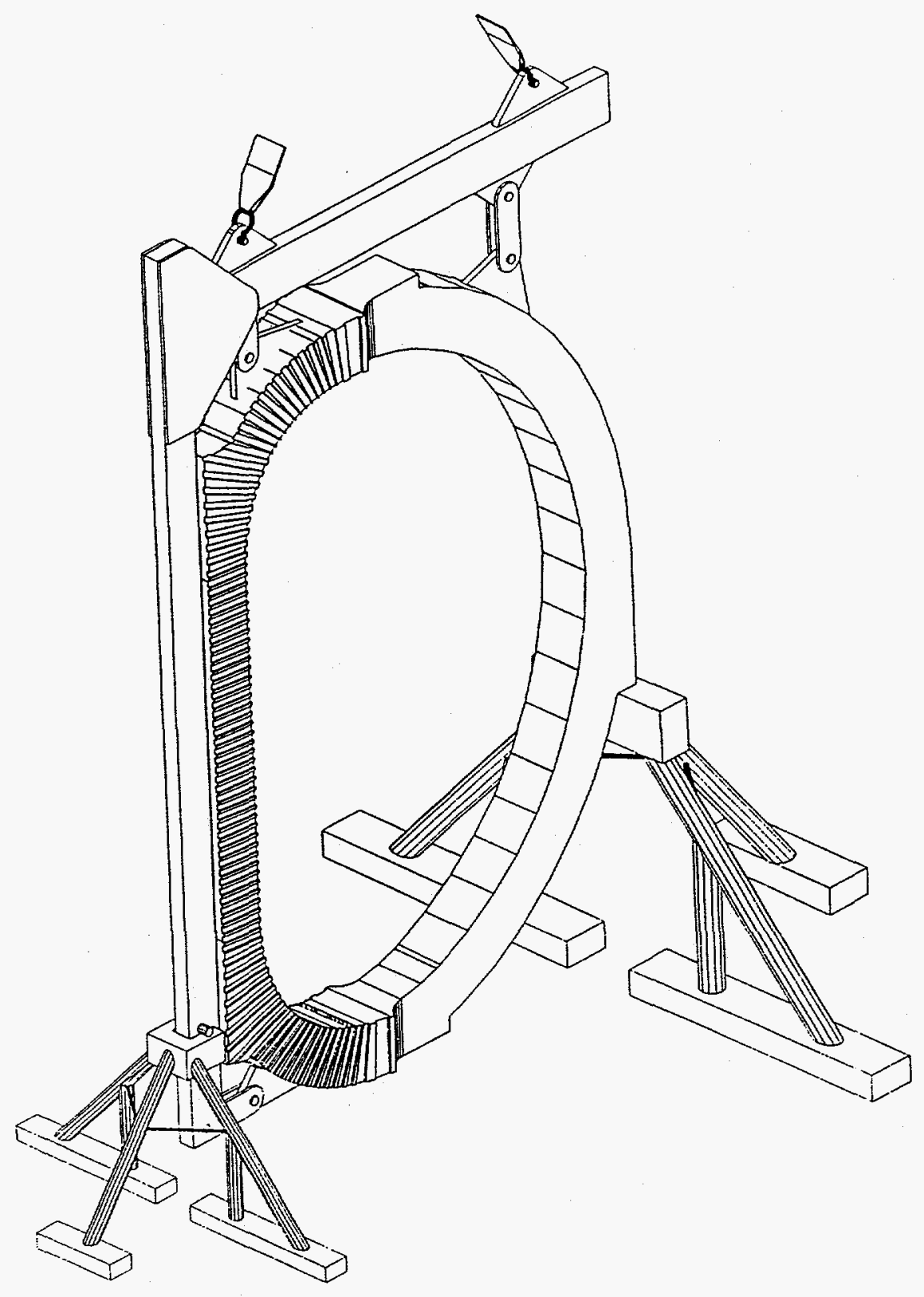

FIGURE 1

TF Coil Support for Characterization 


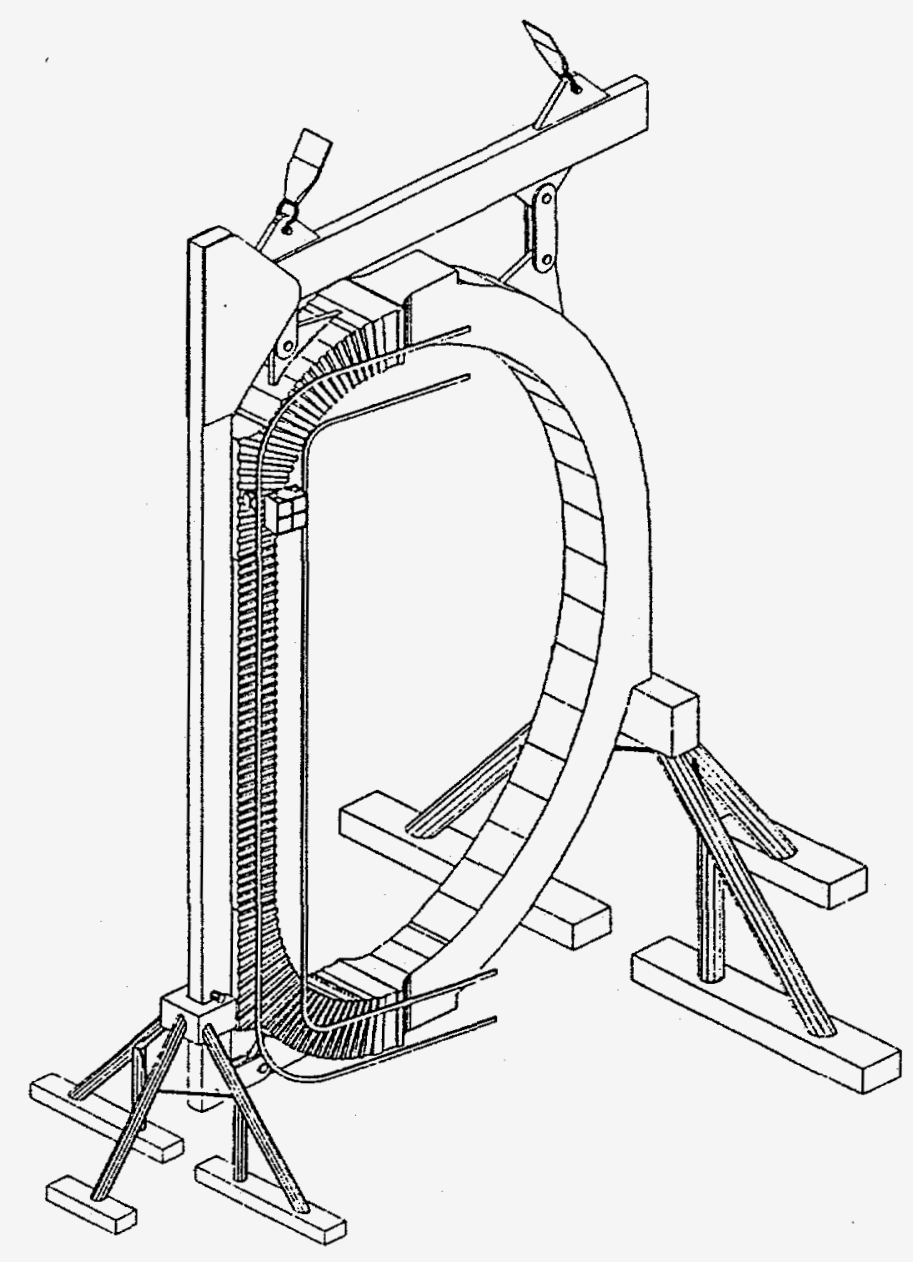

FIGURE 2

TF Coil Being Characterized 


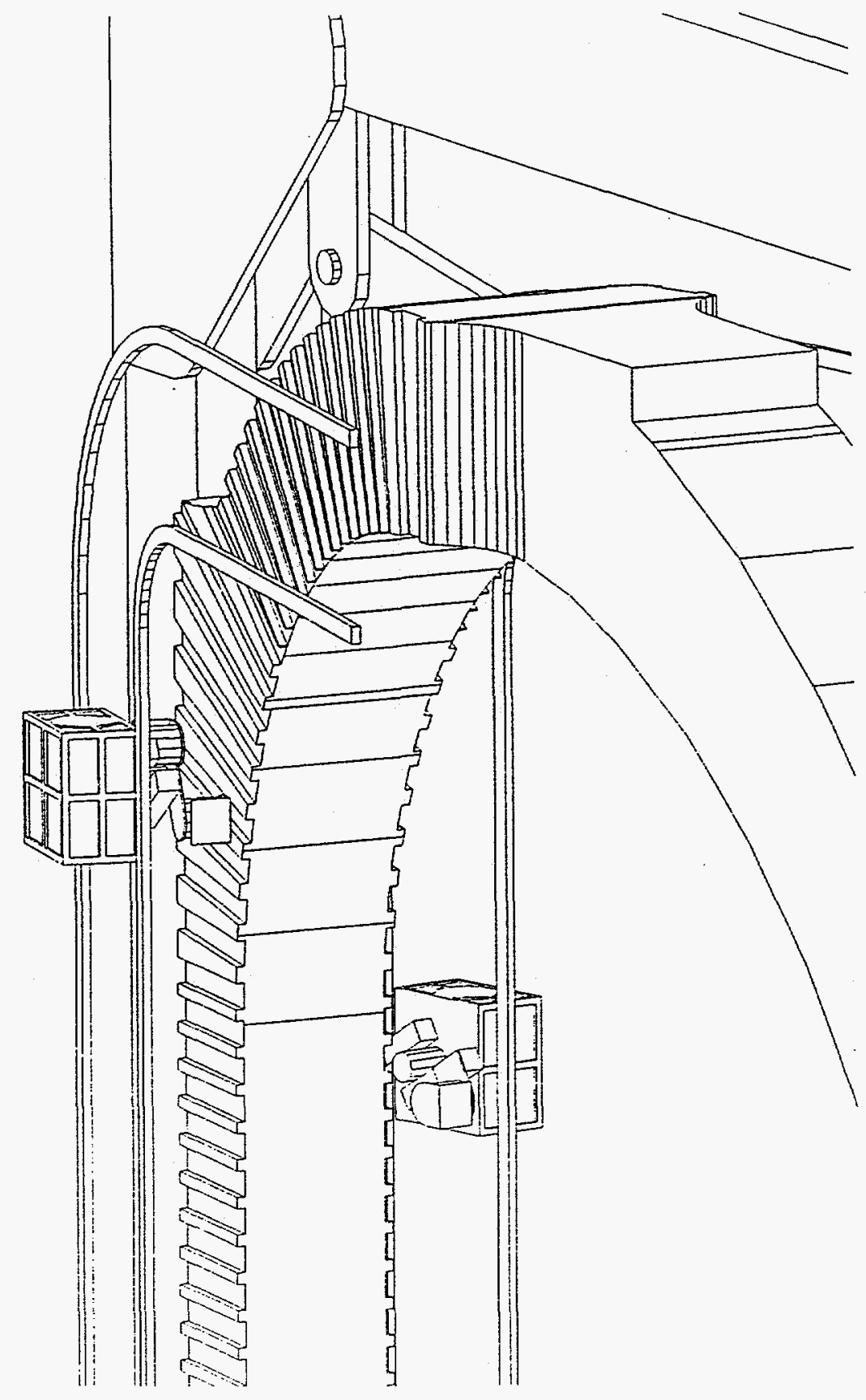

Figure 3

TF Coil Characterization -

Both Sides 

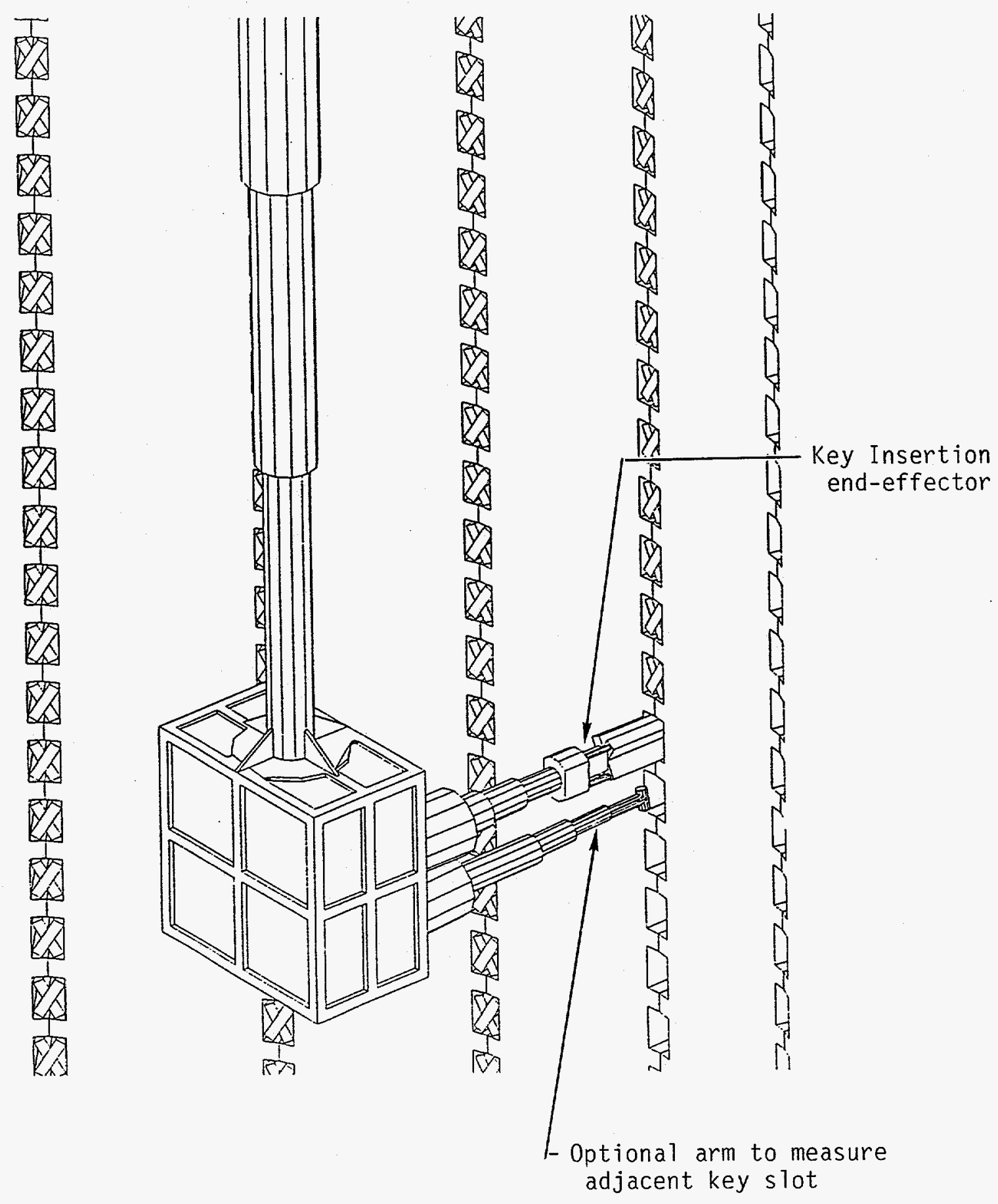

Figure 4

Scissor Key Insertion Robot 


\subsection{Solenoid Coil in Last Initial Installation}

3.3.1. Scissor Keys Installation (57 slots in 24 vertical rows) Installation Steps

1) Lower pallet of keys into work area.

2) Lower robotic device from top to middle elevation (above work platform) (characterization end effector on arm).

3) Characterize first scissor key slot confirming size of inner and outer keys (select both keys).

4) Rotate robot to portable key storage.

5) Select and load first scissor key into insertion device.

6) Rotate robot back to first slot and align key with the slot.

7) Insert outer scissor key into slot, secure key, and retract insertion device.

8) Rotate robot to pick up inner scissor key.

9) Pick up inner scissor key.

10) Rotate robot back to first slot and align scissor key with slot.

11) Insert inner scissor key into place and secure.

12) Align robot to second scissor slot.

13) Repeat steps 3 through 12, a total of 56 additional times to fill one vertical row of scissor key slots.

14) Move robot and temporary key storage pallet to second vertical row of scissor key slots.

15) Repeat scissor key insertion steps 57 times to fill second vertical row with keys in all locations.

16) Repeat steps 12 through 1522 additional times to fill all scissor key slots.

17) Remove scissor key installation robot and temporary storage pallet from reactor.

18) Exchange scissor key end effector with scissor key slot securing device (cover) installation/welding (securing) end effector.

19) Install and secure (weld in place) 1368 scissor key slot covers. 
20) Exchange cover installation end effector with cover inspection end effector.

21) Inspect and confirm the 1368 scissor key slot cover securing method (cover welds).

\subsubsection{Lower Triangular Keys Installation ( 37 slots in 24 rows)}

The lower triangular key insertion robot will insert a key with its keyway center line almost horizontal through a centerline rotation of about $41^{\circ}$. This would require a second robotic device, mounted on the first robot's motion platform, to complete installation of the remaining triangular keys. A third device would probably be required to insert the 4600 lbs. truss keys. Figure 5 shows the first triangular key insertion robot installing a triangular key. It was assumed that the triangular key is a constant cross-section along its length.

1) Characterize 1st slot for acceptability and select 1 st key.

Assume: An azimuthally movable track is pinned in place in line (radially) with the magnet interface to allow radial vehicle motion for key insertion.

2) Receive 1st key next to the Central Measuring Fixture (CMF).

3) Move to 1st slot, spacially align key to slot and insert. Adjust feature to secure key in place with a snug fit.

4) Repeat insertion cycle for all lower triangular keys.

5) Provide permanent retention, e.g., place key. retention cover in place and weld in place.

6) Inspect and accept retention feature.

Note: Key weights (583 lbs average) probably vary from 100 Ibs to $1000 \mathrm{lbs}$ each. 


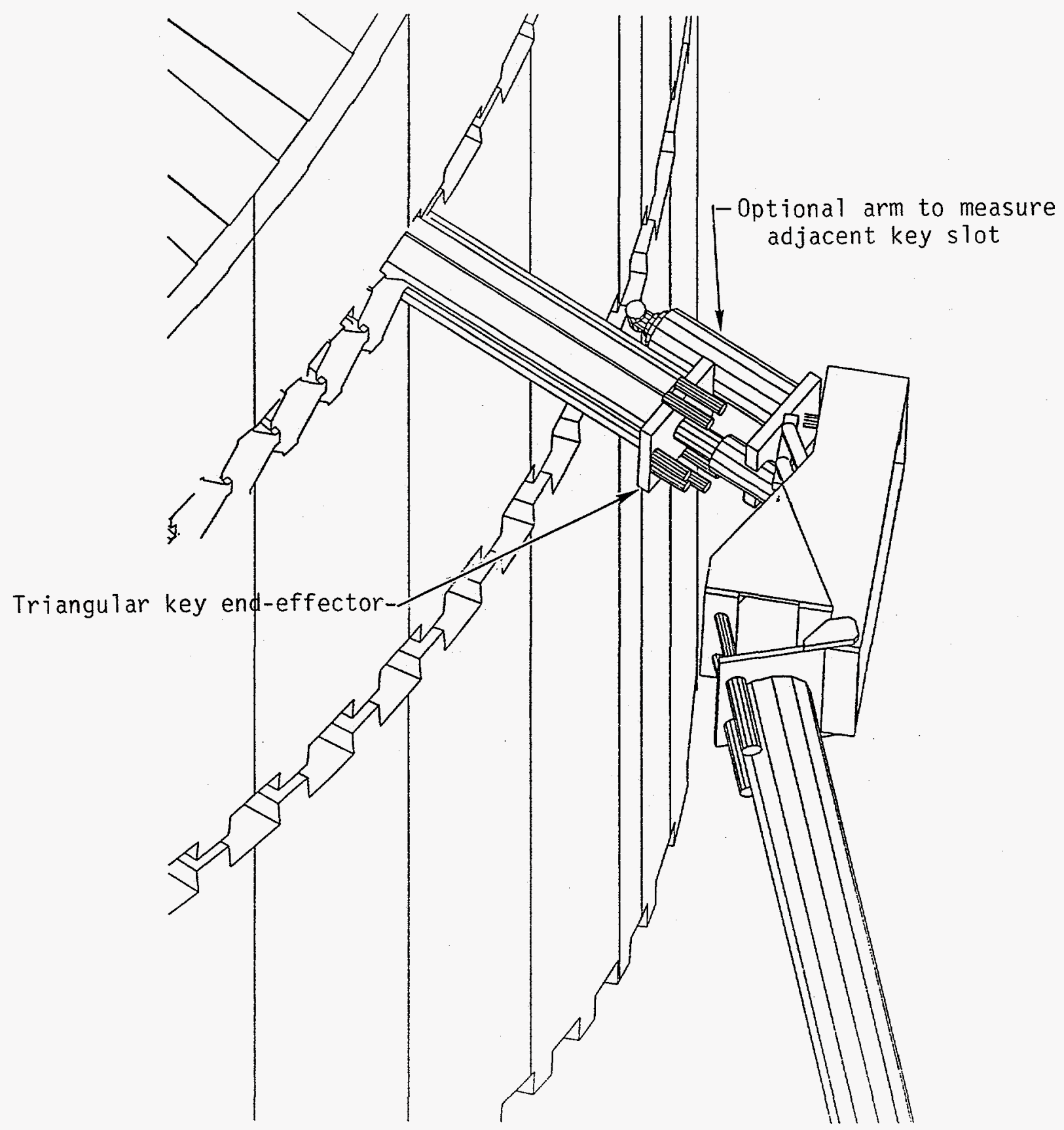

Figure 5

Triangular Key Insertion Tool Looking Up from Below 
3.3.3 Truss Keys Installation ( 4620 lbs each average)

1) Characterize 1 st slot for acceptability, select key.

Assume: Truss slot closed or blocked on vacuum vessel (VV) side.

2) Receive key next to CMF.

3) Position under slot, spacially align truss key and insert truss key into slot. Adjust feature to secure truss key in place with a snug fit.

4) Provide permanent retention e.g., place key retention cover in place and weld in place.

5) Inspect and accept retention feature.

Note: Temporary keys or wedges may be required in upper triangular slot(s) to preclude coil movement.

\subsubsection{Upper Triangular Keys Installation ( 37 slots in 24 rows)}

The manipulator shown in Figure 4 used to install the scissor keys would be used to install the upper triangular keys. The robotic base and end effectors used to install the scissor keys would be exchanged for the triangular key insertion base and end effectors used for the installation of the lower triangular keys. As discussed above, the first triangular key insertion robot has a limited angular motion, from 9:00 o'clock to about 10:15. The key size and weights also increase from about $100 \mathrm{lbs}$ to possibly 300 to 500 lbs. The second, higher capacity robotic base and end effectors would be used to install the remainder of the triangular keys, weighing probably 500 to $1000 \mathrm{lbs}$.

A temporary guide rail might be required on the magnet upper surface to assist in robot alignment for triangular key insertion.

Repeat the steps listed in 3.3.2 above to insert upper triangular keys in slots.

Note: $\quad$ 1) The above steps are repeated for each of the 24 TF coils to install all keys.

2) The above operation proves the operability of the remote maintenance equipment.

3) To shorten the time line, keys may be manual installed in parallel with the remote installation sequences once the remote equipment operation is proven. 


\subsection{Solenoid Coil in Last - Remote Replacement}

Only one set of key removal/replacement robots are needed to replace a failed coil. Following central solenoid removal, the reverse procedure would be utilized twice, to remove the keys on one side of the failed coil, then repeated for the other side.

Installation of keys in the new, replaced TF coil would be done twice, once for each side of the new coil. Key installation would follow the original installation sequence.

\subsection{Solenoid Coil in First - Initial Installation}

\subsubsection{Scissor Keys Installation ( 57 slots in 24 vertical rows).}

It is assumed that all key stops are in place on CS side of TF coil slots to prevent excessive key travel.

1) Rotate $\mathrm{V}$ sectors to allow access for key insertion (as shown in Figure 6). VV cutout is required to accommodate key insertion.

2) Characterize 1 st slot for acceptability and select 1 st key.

3). Insert first key in slot and confirm key inserted to correct depth, then adjust screws for snug fit. Select 2 nd key.

4) Insert key, confirm depth of insertion, adjust screws for snug fit.

5) Repeat key installation on all slots

6) Provide permanent retention, e.g., install cover and weld in place. Inspect and accept weld.

\subsubsection{Lower Triangular Keys Installation ( 37 slots in 24 vertical rows)}

In order to insert triangular keys front the $\mathrm{V}$ side, it is assumed that the cross section of the keys must be constant along its length or have a linear tapper from leading end to back end. For Lower Triangular Key Installation, same as in Section 3.3.2.

\subsubsection{Truss Keys Installation ( $4620 \mathrm{lbs}$ each. average)}

In order to insert truss keys front the VV side, it is assumed that the cross section of the keys must be constant along its length or have a linear tapper from leading end to back end. For Truss Keys Installation, same as in Section 3.3.3.

\subsubsection{Upper Triangular Keys Installation ( 37 slots in 24 vertical rows)}

In order to insert triangular keys front the $\mathrm{V}$ side, it is assumed that the cross section of the keys must be constant along its length or have a linear tapper from leading end to back end. For Upper Triangular Keys Installation, same as in Section 3.3.4. 


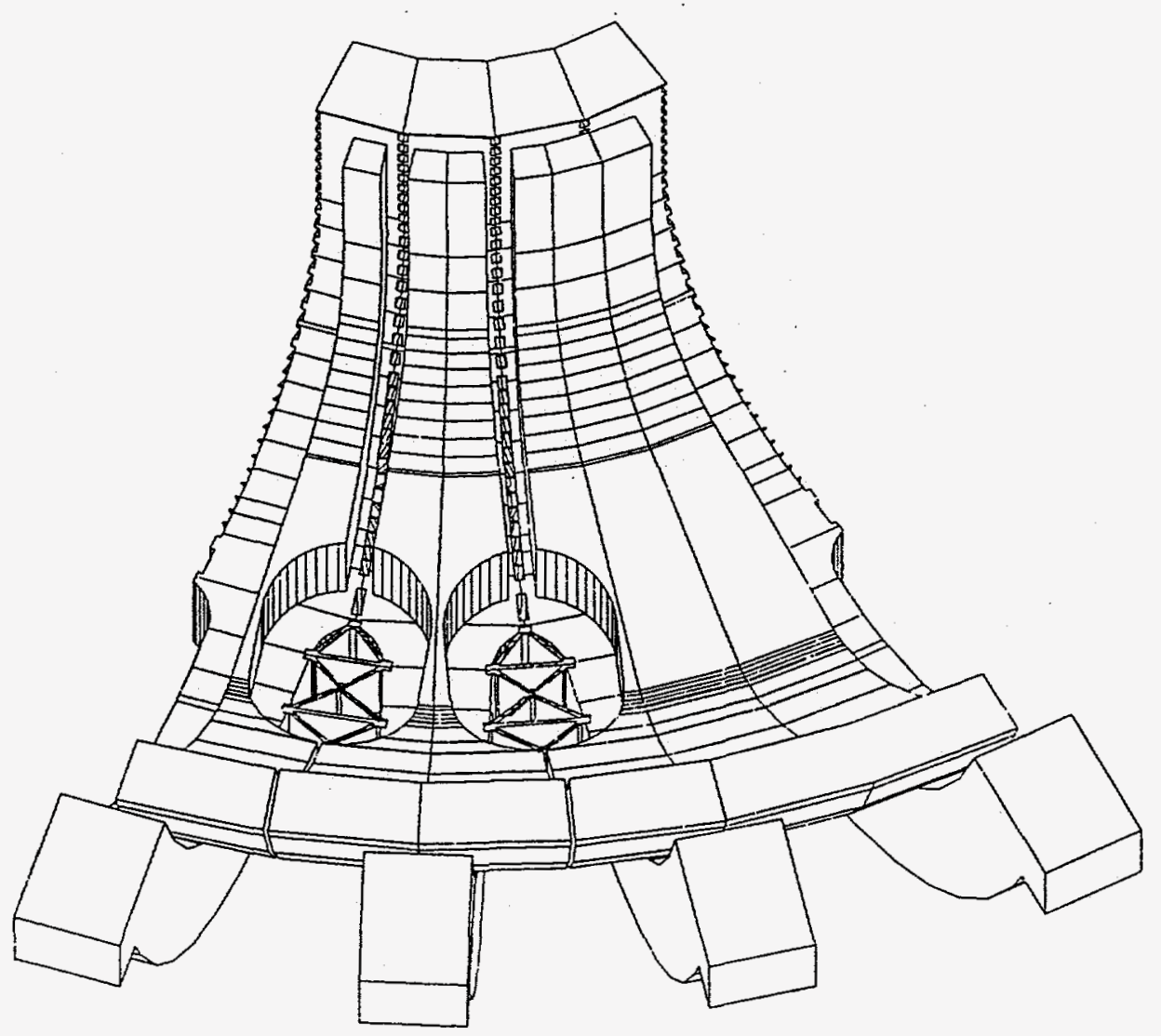

Figure 6

Vacuum Vessel Clearance for

Triangular and Truss Key Insertion 


\subsection{Solenoid Coil in First - Remote Replacement}

1) Cut VV section of failed coil from remainder of VV.

Note: $\quad$ This will require a large section of $\mathrm{V} V$ removal for access to truss keys and triangular keys for removal.

2) Remaining sequence same as described in 3.4.

Concern:

The replacement section of the $V V$ to be installed and the two adjacent sections of the $\mathrm{V} V$ requires large cutouts for access to install truss keys and adjacent triangular keys (both on top and bottom).

Potential Solution:

Investigate a hybrid system for key installation wherein the two truss keys and as many as possible large triangular keys (on the top and bottom of the coil) are inserted and removed from the outside of the coil as dictated by the Central Solenoid/Bucking Cylinder (CS/BC) clearance. The remainder of the triangular keys and the scissor keys are removed and installed from the V side. This approach could minimize VV cutting and welding.

\subsection{Hybrid Installation and Remote Replacement Sequence}

\subsubsection{General Observations}

Remote removal of a failed TF coil also requires large sections of the $\mathrm{V}$ sector to be removed for the Naka Option \#2, along with the adjacent mating sides of the good coils VV. Reinstallation of a new TF coil and its VV sector presents the same VV clearance problem for shear key insertion. Utilization of both key insertion from the inside for the smaller keys and from the outside for the larger keys should minimize the large cutouts of the $\mathrm{VV}$ sectors (at least the last sector of the $\mathrm{VV}$ and its adjacent $\mathrm{V}$ sector to be welded)

Utilization of the hybrid concept would significantly reduce the VV clearance requirements for key installation and the resulting $\mathrm{V}$ segment welding problem.

\subsection{TF Coil Shear Keys Recommendations}

The present state-of-the-art for remote handling is about $50 \mathrm{lbs}$, which is the approximate weight of the half length scissor keys. Though the design of the full length triangular keys is not complete, the triangular key weight starts at about $100 \mathrm{lbs}$ for the lightest key and rapidly increases to over 1,000 lbs for the outer keys.

The installation robot should be checked out early in the program to confirm its operation. More importantly, the key design should be analyzed to determine if full length solid steel keys are required to react the shear loads or if lighter weight, hollow keys could be utilized. 
The 4,000 to 5,000 lbs truss key installation robot is an even more challenging design problem. Large lead in clearances must be provided. Truss key installation difficulties approach the difficulties of the solenoid coil in last installation problems. Though the shear key installation appears feasible, but difficult, every effort should be made to lighten the key weights.

Cast in place keys should be considered if they meet the shear load requirements. Shear loads are transferred into "compacted, non-conductive electrical insulation" in compression. The yield strength should be much less than the metallic shear keys. A low melting point alloy in a flexible bladder might be used to eliminate the slot inspection/correction and key machining costs. Thermal expansion matching of the cast in place key and slot is an important requirement. It is envisioned that the low melting point material could contain particulated materials to tailor the thermal expansion to be compatible with the slot.

\section{TF COIL SHEAR KEYS INSTALLATION TIME LINE}

The following is an estimate of the TF coil installation time line for the Naka Option \#1. The other options addressed appear to require about the same time for shear time installation. The time estimate is based on the following assumptions:

- The time sequence is based on an eight hour day, 5 days per week, one robot operation (multiple shift operation could shorten the estimate).

- Each remote installation robot design probably requires 15 to 25 key insertions for both the scissor and triangular keys to prove their remote operability. Subsequent to the robot operability confirmation, up to 3 manned teams could operate in parallel with the robot to shorten the time estimate.

The time estimate shown Figure 7 for one row of keys based on the above assumptions is 111.7 hours or 2.79 weeks. The 24 rows of coils would then require 66.96 weeks of key installation time. A 24 hour/day, 7 days/week operation would reduce the installation time by a factor of 4.2 or reduce the schedule down to 15.9 weeks. Three manned crews working in parallel with the robots could reduce the key installation time down to about 4 weeks. 


\section{Figure 7. REMOTE MAINTENANCE KEY INSTALLATION TIMES}

FOR ONE ROW OF SHEAR KEYS

Key Installation

a) Scissor

b) Lower Triangular

c) Truss

d) Upper Triangular

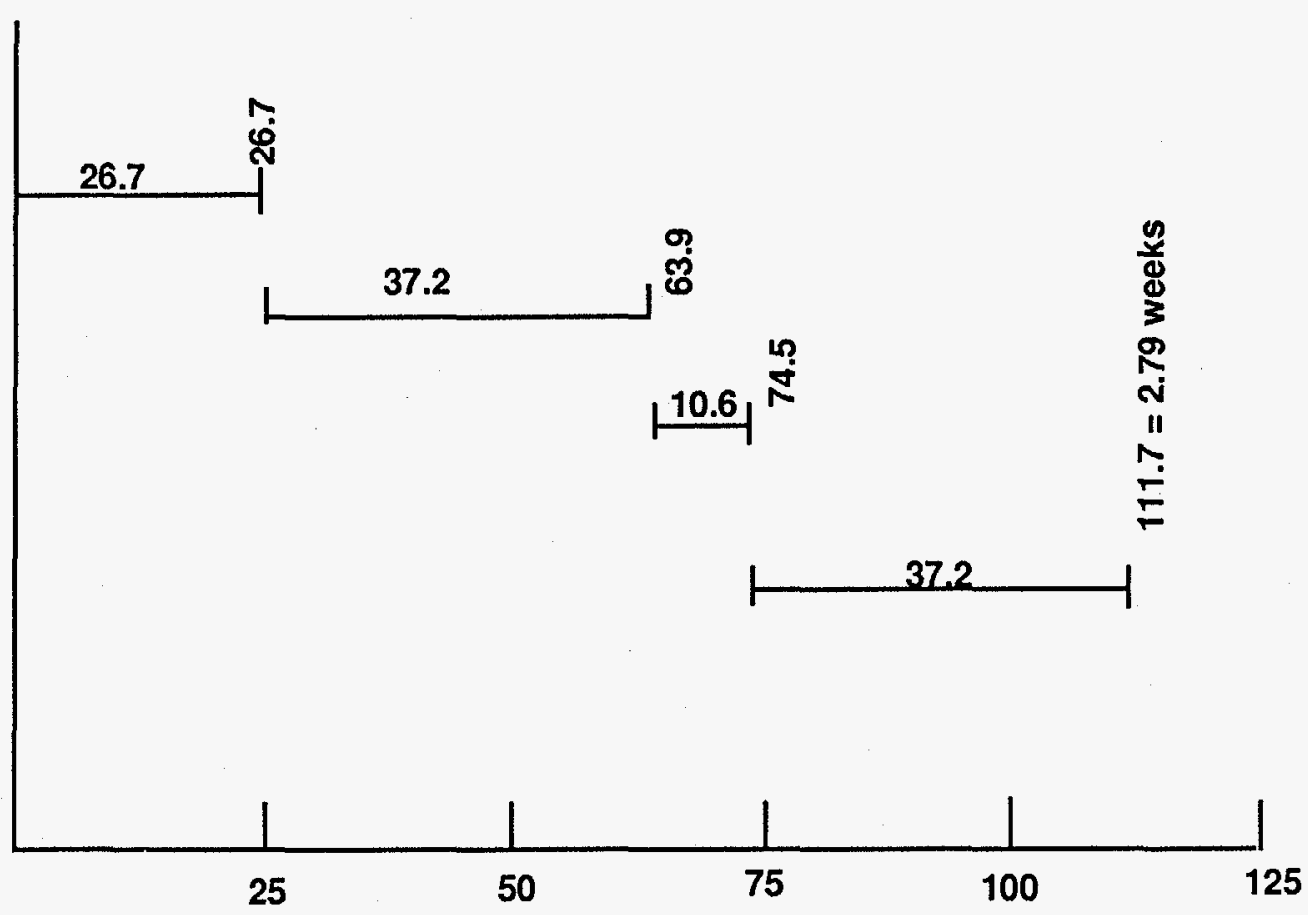

ELAPSED TIME, hrs 


\title{
5. REFERENCES
}

1) Zbigniew Piec, "Initial Assembly Procedures for the ITER Support Structure and Magnet Components", Naka Option \#1, October 4-6, 1994, Garching, Germany.

2) Zbigniew Piec, "Initial Assembly Procedures for the ITER Support Structure and Magnet Components", Naka Option \#2, October 4-6, 1995, Garching, Germany.

3) Selcom, Optocator Gauge Probes, Product Information, Valdese, North Carolina, USA, (704)874-4102.

\section{DISCLAIMER}

\begin{abstract}
This report was prepared as an account of work sponsored by an agency of the United States Government. Neither the United States Government nor any agency thereof, nor any of their employees, makes any warranty, express or implied, or assumes any legal liability or responsibility for the accuracy, completeness, or usefulness of any information, apparatus, product, or process disclosed, or represents that its use would not infringe privately owned rights. Reference herein to any specific commercial product; process, or service by trade name, trademark, manufacturer, or otherwise does not necessarily constitute or imply its endorsement, recommendation, or favoring by the United States Government or any agency thereof. The views and opinions of authors expressed herein do not necessarily state or reflect those of the United States Government or any agency thereof.
\end{abstract}




\section{Stophon E. Hofner} Ealas Engineor

\section{Append ix?1}

P.O. Box $280 \square$ Vuldose, N.C. 28680

Tel. 704/4744102 $\square$ Fax. 704/874-3896

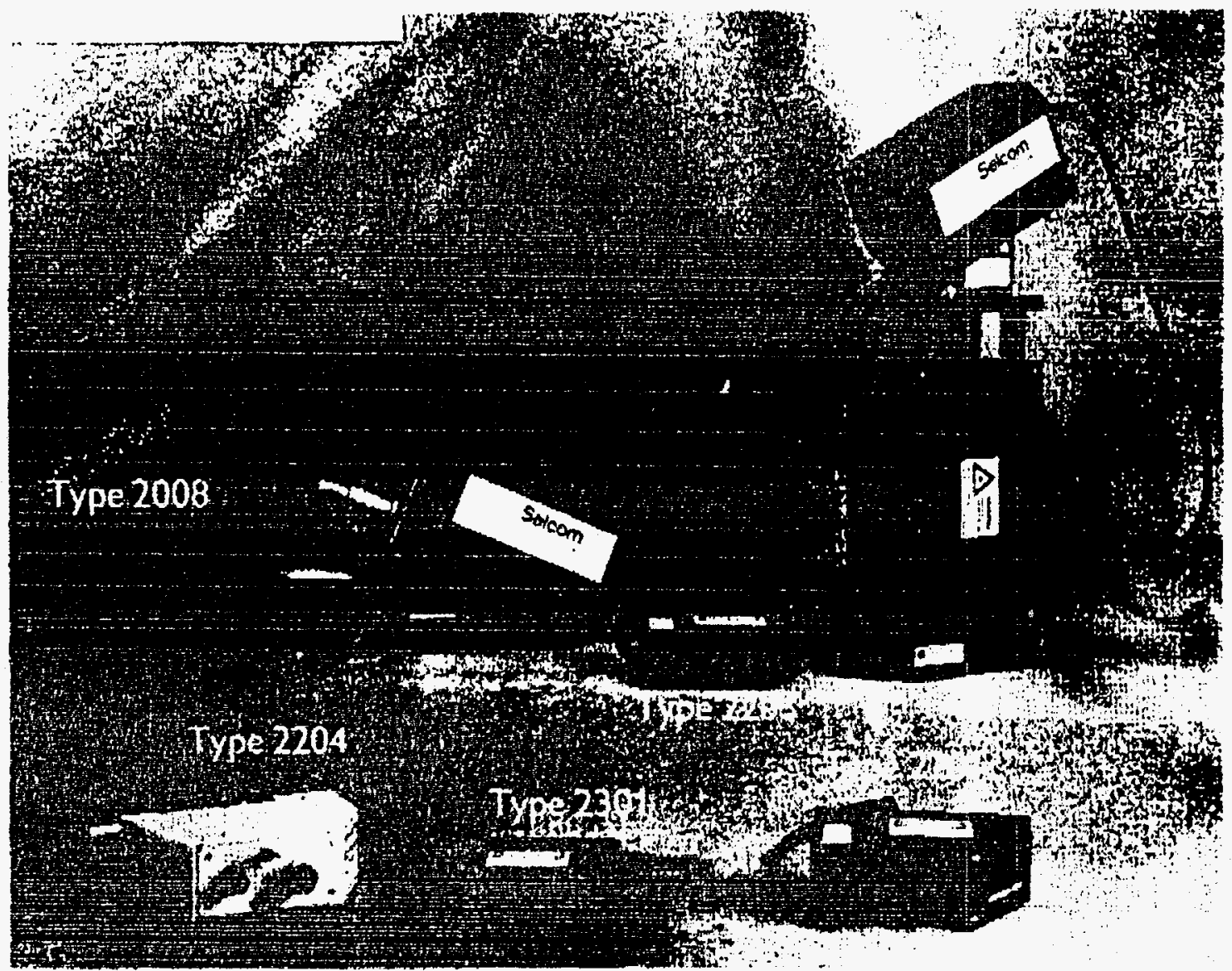

\section{Optocator Gauge Probes}

The Optocator is an opto-electronic, non-contact measurement produch By means of laser beam triangulation, it rapidly provides precision measurement data for variables such as thichess, heigh, width, length position, level, surface proflle, flatiess, contour, displacement and vibration - on almost any material regardless of the sufface's texture, temperature, density or color.

Since measurements are beirg mado with pulse repetitions of 16,000 or 32,000 times/eecond meastrements can be rnade on rapidly moving objects anc in high ambisnt light conditions.

For example, you can meagure the level of molien iron, the pevelnent condition on highways or the thickness of exnuded nubber.

Several types of Optciator gauge probe have been developed to wuit different user requirements.

For induatrial applicatons involving rough envirotmontal conditons the Optocator can be provided with dust and best protection, auch as cooling jacket and an air purge syptem.

This brochure describes the basic function of the Optccator gange proba, and the standard types ayailable for various applications. 


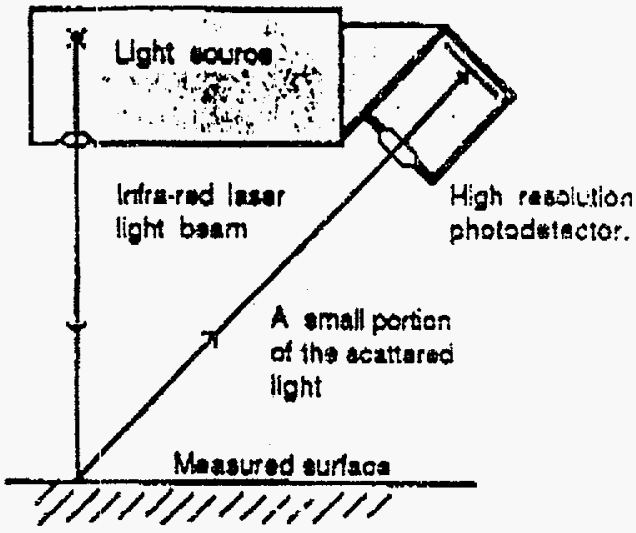

Flgura la / Heasurement principle (optical triangulation by laser light)

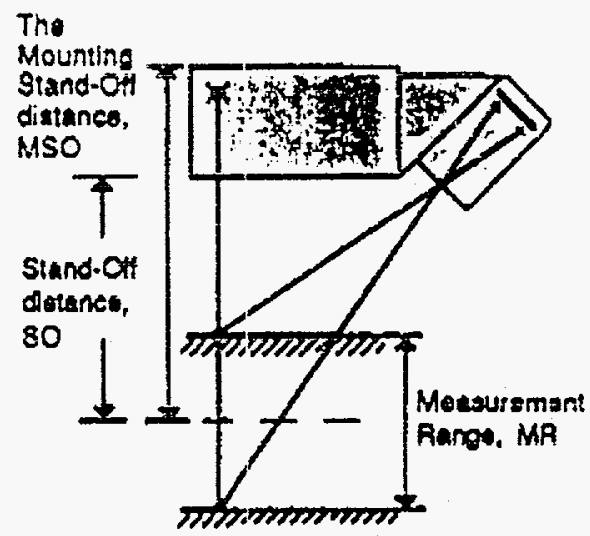

Figure ib MR, so and MSO difinitiont

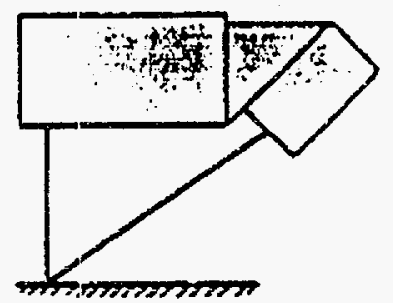

Figure 2a Singleprobe configurztion (lavel, diaplacament, vlbration, ete.)

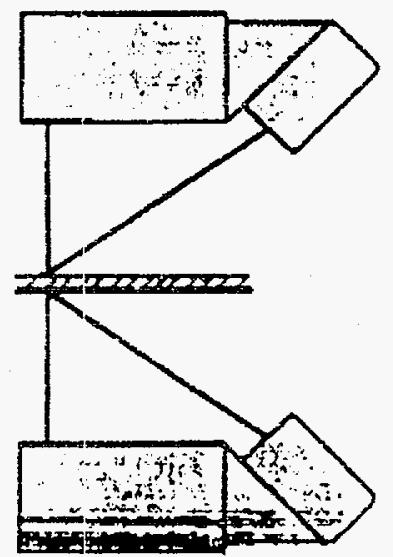

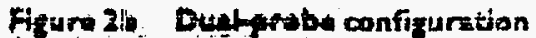

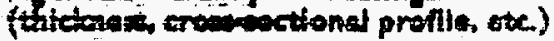

Measurement principle

The major components of the Opwrator gauge prolve are:

- the light bourcs (aniniensity consrolled, pulse modulated IR laser diode) with a focuting lena

- the camera unit with a focusing lend and a onedimensional, high-resolution photodetector.

- the probe processing unis (PPU) with sigral processing electronics For some types of probe the PPU is integrated into the probe housing: for other types it is romoto.

Briefly, this is how the Opturator works:

1. The light source focuses a light beam onio a iny spot on the surface of the measured object.

2. A small portion of the scatiered light from tbis spot is focused onto the position gensicive photedotector (an image of the spot on the surface).

3. The photodetector provides a signal corresponding to the location of the imags The signal processor then converts this signal into a measured distance between the guage probe and the measured object.

4. Any change in this diatance vill result in a change of the iocation of the focused light spot on the protodetector and, bence, the signal given to the processor will be different.

Three major variabies:

The Measurement Range (MRI is the "window" within vibch the mesaured surface mut be located, if its position is to be registered by the photodeter tor. For the standard types of Optosetor gange probe, MR ranges from 8 to $1024 \mathrm{~mm}$.

The Stand-Off diatanco (SO) is the distance between the gauge probe and the center of the MR. SO typically ranges from 95 to $1200 \mathrm{~mm}$.

The Mounting Stand-Off distance (MSO) is the distance between the mounting surface of the $G P$ and the centre of the $M R$.

\section{Signal processing}

The signal processing within the the gauge probe (consisaing of analog and digital parts - sec finure 3) eliminatos pussible interference from ambient light and compensates for rapid varianos in surface conditione by utilizing the technique of high apeed pulsing of the light aource combined with subsequent filtering and demcidulation of the received light pulse.

The output iugral from the gauge probe is a ready-touso linearized diatance value between the gauge probe and the measured surface. This signal is tranamitred with full bundwidth in serial digital form over long distances, even in very hostle environnent

Subsequent signal processing such as dats averaging and filtering can be periormed in either a CPL 1007 or 1004, or a MEEbus-companable interface board. Anslog volizge current and digital output formats of the processed sis nal are available which provide eacy interfacing to external PC, PLC and other data collection/processing devices.

\section{Output specifications}

Digital oupui 15 bit serial. inciuding 12 bit mezsurement data and 3 bit

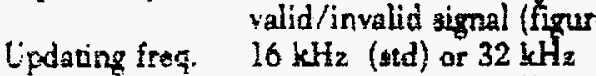

Bandwidth

Mas land:

$20 \mathrm{kHz}$ (atd) or $5 \mathrm{kHz}$ (10kHz)

- voltage

(OH = Output High, OL = Oupur Low)

- current
$\mathrm{L}_{\mathrm{OH}}>2.0 \mathrm{~V} . \mathrm{L}_{\mathrm{OL}}<0.8 \mathrm{~V}$

${ }^{\mathrm{OHH}_{\mathrm{OH}}}>40 \mathrm{~mA}$. $\mathrm{IOL}<-40 \mathrm{~mA}$ 

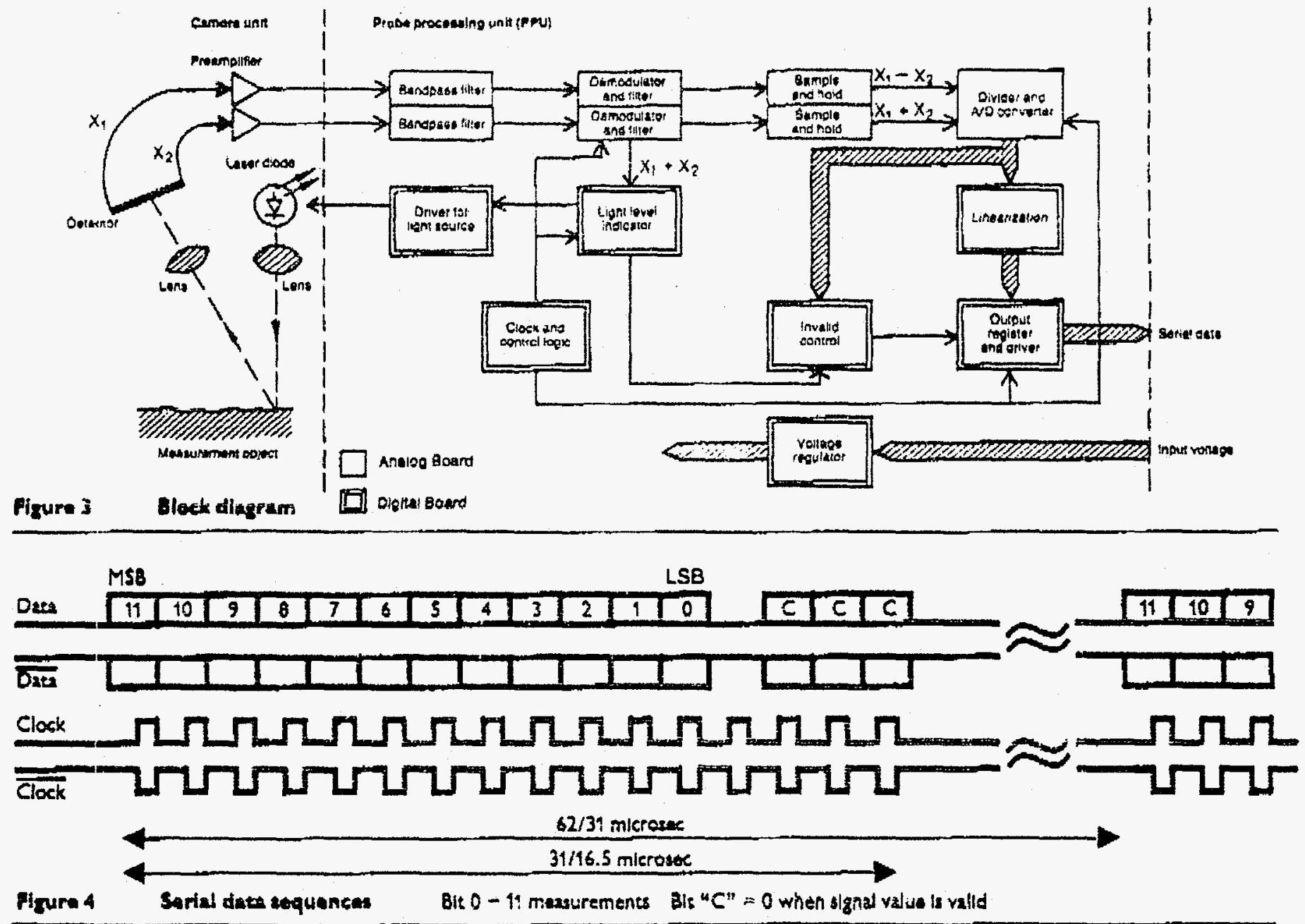

\section{Error definitions}

Total arror - Non-linearity + Inaccuracy + Temperature coeff. + Noise ("worst case condition") YOTE: The total emor car be cousuderably raduced by using a good calibration rouvine.

1. NCN-LINEARITY

Max deviation from a atraight line calculated by the RMS method for all meanured values (bett line fit).

Typical non-linearity: $\pm 0.025 \%$ of $\mathrm{YR}( \pm 1 \mathrm{LSB})$

Max non-linesrity: $\quad \pm 0.050 \%$ of MR ( \pm 2 LSB)

\section{INACCURACY}

Max deviation between a correct line and the calculated line (ree non-linearity).

Max. insecurrey: $\quad \pm 0.050 \%$ of HR (= 2 LSB)

\section{TEMFERATURE COEFFICIENT}

Max deviecion per ${ }^{\circ} \mathrm{C}$ between the straight line at room tempersture (we non-ilnesrity) and the same type of line at another tempe ratuine.

Max temp. coeff: $\quad 0.01 \%$ of $M R / \pm C(0.4$ LSB/tC)

4. NOISE

Bandwidth

Yoise factor

$2 \mathrm{kHz}$

max $\pm 8 \mathrm{LSB}$

$\max \pm 1 \mathrm{LSB}$

Trupicai value (RMS)

$0.07 \%$ of $M R$

$0.01 \%$ of $\mathrm{MR}$

MR = Measuremont Range (definition on page 2)

LSB - Loast Significant Bit (rebolution or scale factor)

RMS - Root Mean Square (a math. calculation technique)

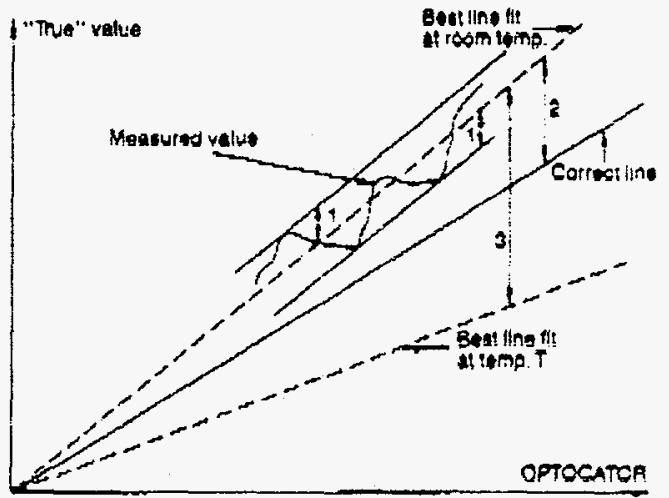

Figures Error dofinition:

Resolution

LSB (least sipnificant bit) $-0.025 \%$ of MR, which gives the following scale factors:

\begin{tabular}{cc}
\hline$M R$ & $L S B$ \\
\hline $8 \mathrm{~mm}$ & $2 \mu \mathrm{m}$ \\
$16 \mathrm{~mm}$ & $4 \mu \mathrm{m}$ \\
$32 \mathrm{~mm}$ & $8 \mu \mathrm{m}$ \\
$64 \mathrm{~mm}$ & $16 \mu \mathrm{m}$ \\
$100 \mathrm{~mm}$ & $25 \mu \mathrm{m}$ \\
$128 \mathrm{~mm}$ & $32 \mu \mathrm{m}$ \\
$256 \mathrm{~mm}$ & $64 \mu \mathrm{m}$ \\
$362 \mathrm{~mm}$ & $90 \mu \mathrm{m}$ \\
$512 \mathrm{~mm}$ & $128 \mu \mathrm{m}$ \\
$1024 \mathrm{~mm}$ & $256 \mu \mathrm{m}$
\end{tabular}

Note: The "scale factor" is an exact figurs. 


\section{Technical specifications}

LIGKT SOURCE:

Lasar diode

$\begin{array}{ll}\text { Typw } & \text { GaAs } \\ \text { Class } & \text { IIl b } \\ \text { Wavelength } & 870 / 820 \mathrm{~nm} \\ \text { Pulse duration } & 350 \mathrm{ng} / 32 \mu \mathrm{s} \\ \text { Peak power } & 112 / 20 \mathrm{~mW} \\ \text { Avenge power } & 10 \mathrm{~mW}\end{array}$

ENVIRONMENTAL:

Shack

Vitiration

Tercperahure:

- operating

- storage

Relative humidity $10-90 \%$, non-condenaing
PHOTODETECTOR:

Type Single dement photo lateral diode.
POHER SUPPLY REQUREMENTS:

$+20 Y( \pm 1 \mathrm{~V}) \quad \max 110 \mathrm{~mA}$

$-20 \mathrm{~V}( \pm \mathrm{l} V) \quad \max 100 \mathrm{~mA}$

$+15 V(+5 /-4 \mathrm{~V}) \quad \max 160 \mathrm{~mA}$

$+18 \mathrm{~V}(+5 /-3 \mathrm{~V}$ ) $\quad \max 150 \mathrm{~mA}$ (laser on)
Complies with IEC 68-2-27

Complies with IEC 68-2-6/83

$0^{\circ} \mathrm{C}$ to $40^{\circ} \mathrm{C}$ (min. interval)

$-30^{\circ} \mathrm{C}$ to $70^{\circ} \mathrm{C}$

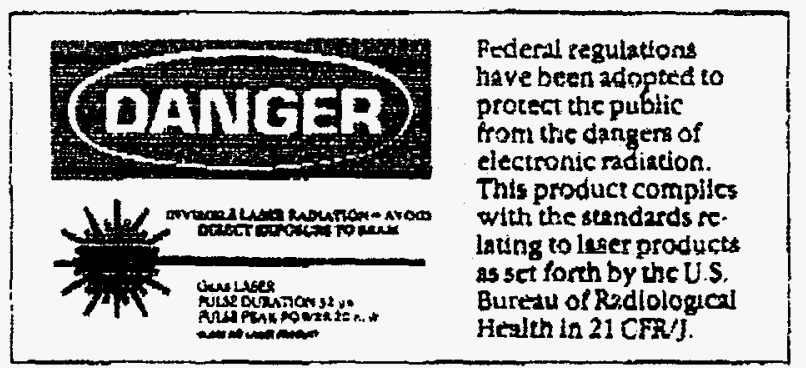

Optocator Gauge Probes (std)

\begin{tabular}{|c|c|c|c|c|c|c|}
\hline Type & 2005 & 2008 & 2201 & 2203 & 2204 & 2301 \\
\hline$M F, m m$ & $128 ; 256 ; 512 ; 1024$ & $128: 256: 362$ & $8: 16 ; 32$ & $32 ; 64 ; 100$ & $32 ; 64$ & $8 ; 16$ \\
\hline $\mathrm{SO}, \mathrm{mm}$ & $710 ; 710 ; 1000 ; 1200$ & $390 ; 390 ; 536$ & 95 & 180 & 170 & 95 \\
\hline $\mathrm{MSO}, \mathrm{mm}$ & $845 ; 845 ; 1135 ; 1335$ & $467 ; 467 ; 613$ & 186 & 257 & 260 & 177.5 \\
\hline Length, $\mathrm{mm}$ & 460 & $285 ; 285 ; 362$ & 145 & 120 & 155 & 95 \\
\hline Height, mm & 200 & 180 & 91 & 79 & 107 & 83 \\
\hline Width, mm & 90 & 90 & 50 & 44 & 50 & 25 \\
\hline Woight, kg & 7.7 & $2.8 ; 2.8: 3.0$ & 0.900 & 0.600 & 0.650 & 0.310 \\
\hline $\begin{array}{l}\text { Ligght गpot, } \\
\min (*)\end{array}$ & $1 \times 13: 1.7 \times 8 ; 1.5 \times 15: 4 \times 8$ & $2 \times 5: 2 \times 5: 1 \times 9$ & $0.1 \times 1.5$ & $0.2 \times 2.5$ & $0.1 \times 1.8$ & 00.1 \\
\hline
\end{tabular}

(*) nominal size, at the center of MR. Note: All rypes excopt 2005 have separate PPU:s. The issued data concerns the gauge probes orly. Specifications aubject to change without previous notification.

Swoden

SELLCM AB

Bor 280

543326 PARTILLE, Sweden

Tolophone: -4831447440

Thlatax: +483144 BI 70

THiax: 27304 8ELCOM $S$

\section{Qermany}

SELCOM MBSSYSTEM GMAH

Brucntoid 100

D-4150 KAEFE:D 12. Germany

TGiepnone: $+4 \theta$ 21 51 58075

bletax: +49215 ! 500048
UBA

SELECTIVE EIECTRONIC, INC 21904 Maloos:

SOUTHFIELO MI 48075 , USA

Tolopitone: + 3133855800

Tolefax: - $1313 \$ 353263$
Rogional offlce

SELECTIVE ELECTRONIC, INC P.O. Bor 250

VALDEGE NC 29 BSO, UEA

Tolephone: +17048744102

Toletax: + 704 gra 3868 

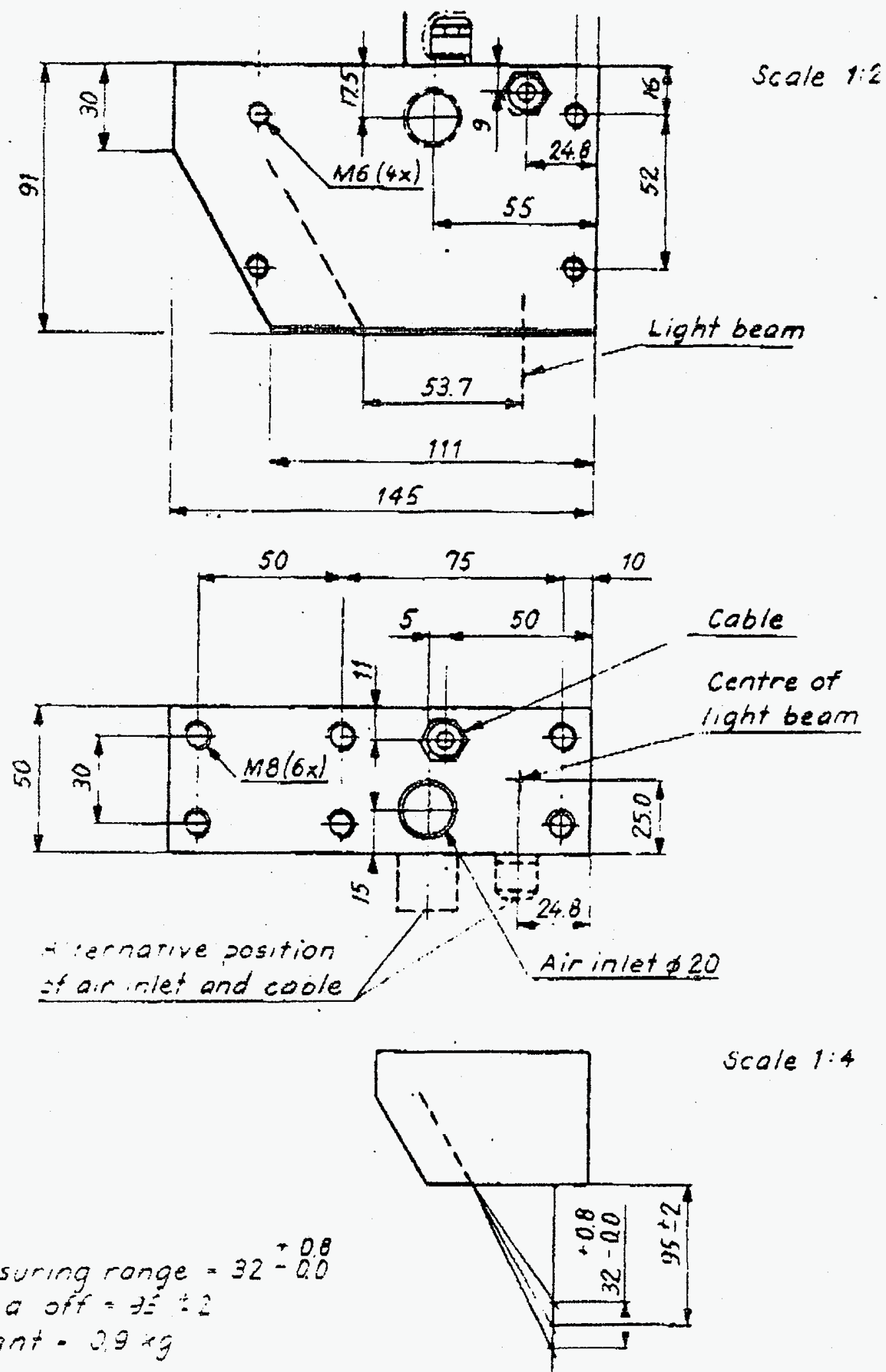

Scole 1:4

Meosuming ronge $=32=0.0$

stane off $= \pm E: 2$

Neignt - ?9+9

\begin{tabular}{|c|c|c|c|c|c|c|c|c|}
\hline Doters & $\Delta n$ & \multicolumn{2}{|c|}{ anongming } & & instapied & 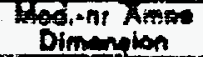 & \multicolumn{2}{|c|}{ An m } \\
\hline 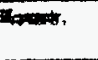 & 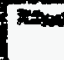 & $x \rightarrow 16$ & tontr. & stant. & awd & $9: 2$ & Enther & $2 \ln =$ \\
\hline & & & $\begin{array}{l}\text { GA } \\
D I A\end{array}$ & & $\begin{array}{l}O B E T \\
A L O R\end{array}$ & $\begin{array}{l}E 2201 \\
\text { IING }\end{array}$ & $\begin{array}{r}\text { Aev } \\
2\end{array}$ & $\frac{-82112}{-501}$ \\
\hline
\end{tabular}

